\title{
Analysis of Neuronal MPPT performance for Photovoltaic system
}

\author{
RAJONIRINA S. Jeannie*, RAZAFIMAHENINA J. Marie**, RAOELIVOLOLONA Tefy ${ }^{* * *}$ \\ ANDRIANANTENAINA Chrysostome ${ }^{* * * * *}$ \\ *EDT-ENRE, University of Antsiranana, \\ **: Information and Communications Sciences and Technology Department, Higher Polytechnic School, \\ *** Information and Communications Sciences and Technology Department, Higher Polytechnic School, \\ ${ }^{* * * *}$ EDT-ENRE, University of Antsiranana,
}

DOI: 10.29322/IJSRP.11.12.2021.p12024

http://dx.doi.org/10.29322/IJSRP.11.12.2021.p12024

\begin{abstract}
-
The neural network is part of artificial intelligence techniques which use has increase exponentially in various fields, due to their ability to manage complex systems specificities.

In this paper, this technique is used to improve the efficiency and optimization of a stand-alone photovoltaic system on varied temperature as well as the sunlight. Finding the maximum power consist on combining an MPPT control based on artificial neural networks with two cascaded PI correctors. The proposed command uses the retro propagation algorithm which aims to control the duty cycle of a SEPIC converter in order to ensure the matching of impedance between the PV generator and the load. The model of a photovoltaic cell as a single-diode is chosen in order to verify the behavior of the PV generator under varying external conditions. The analysis and comparison of the obtained results with the most used method will show the performance and effectiveness of this approach.
\end{abstract}

Index Terms- Neural control, SEPIC, PI regulator, photovoltaic system, neural network

\section{INTRODUCTION}

$\mathrm{T}$ The photovoltaic generator (GPV) is the only direct converter which transform light into an electrical energy, and offers the possibility of producing electricity directly from a renewable and widely available resource [1]. An important characteristic of solar panels specify that the maximum available power is only supplied at a single operating point, defined by a known voltage and current value, called the point of maximum power (PPM). In addition, this point is not fixed, its location moves according to the irradiation and the temperature of the solar cells as well as the load.

The position of the PPM is unknown, but can be located, either with computational models or search algorithms. MPPT (Maximum Power Point Tracking) techniques are used to permanently maintain the operating point of the photovoltaic generator at its PPM.

Researches works on the MPPT area are normally grouped into two categories: the first concerns the optimization of the DC-DC converter; and the second refers to the maximum power point tracking algorithm.
The direct power obtained from the panel is low and nonregulated. The DC-DC converter ensures the impedance matching between the PV generator and the load. The choice of converter is then based on the advantages offers by each of them after comparison, such as the effect on output voltage and current ripples, reduction of switching losses and the influence of filter elements. [4].

Several works have dealt the problem of finding the operating point in order to get the maximum energy from PV modules using different MPPT methods. However, the non-linearity characteristic of PV modules, their dependencies on temperature, sunlight and the level of degradation make the implementation of these methods more complex.

These methods also show poor convergence or oscillation around the optimum point of power on normal operating conditions, when meteorological conditions vary.

Among the research works that deal with this topic, the use of techniques based on artificial intelligence marks the important point [4]. Some published works deal with neural networks to extract the PPM, but, most of them use the Boost converter and the predefined blocks in Matlab Toolbox [5] [6]. The latter gives good results, but on the other hand, it is very specific, and difficult to implement.

In order to assess the efficiency of the proposed algorithm, a precision model for photovoltaic panels, based exclusively on the parameters of the datasheet is treated. The proposed algorithm has been implemented in Matlab for its verification under a wide temperature range and sunshine conditions based on the precise model.

\section{SYSTEM PRESENTATION}

Figure 1 show the structure of the system which is composed by three blocks such as the PV generator, the proposed adaptation stage. The control block is composed by the MPPT combined with PI regulators in order to ensure the pursuit of the optimum operating point [1]. It is a simple storage-less system which supplies AC loads of power in the order of a few kilowatts. 


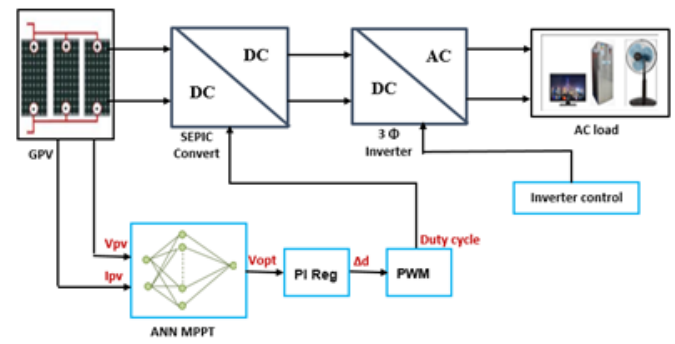

Figure 1. Block diagram of stand-alone PV system

\section{MODULE MODELING}

The elementary component of the photovoltaic panel is the photovoltaic cell. To establish the mathematical model of the PV cell, it is first necessary to find its equivalent in electrical circuit. The latter is formed by a P-N type junction. Thus, to have a photovoltaic cell, it is necessary to produce a $\mathrm{P}-\mathrm{N}$ junction diode structure in a doped silicon material in parallel with an ideal current source providing an $\mathrm{I}_{\mathrm{PH}}$ current proportional to the incident light power.

Under darkness, the equation (1) represents the model of the diode:

$$
I=I_{s}\left[e^{q\left(\frac{V}{n K T}\right)}-1\right]
$$

On light, we have the equation (2):

$$
I=I_{p h}-I_{s}\left[e^{q\left(\frac{V}{n K T}\right)}-1\right]
$$

Where, $\mathrm{q}$ is the electron charge $(\mathrm{q}=1.6 .10-19 \mathrm{C})$.

$\mathrm{K}$ : the Boltzmann constant $(\mathrm{k}=1.381 .1023 \mathrm{~J} / \mathrm{K})$.

$\mathrm{T}$ : the effective temperature of the cell in kelvin

I sat: the reverse saturation current of the PN junction

An equivalent model of the ideal cell composed by a diode in parallel with a current generator is represented in figure 2 . When the contact resistance and the ohmic losses are considered as in the real case, a series resistance (Rs) and a parallel resistance (Rp) [2] [8] must be associated to the equivalent diagram.

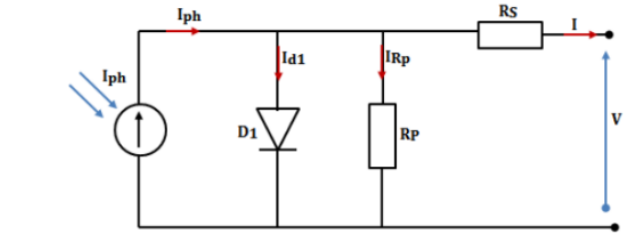

Figure 2. One-diode model of a cell

The role of this circuit can be formalized by a system of equations (equation (3)) obtained from Kirchhoff's laws.

$I=I_{p h}-I_{d}-I_{R p}$ (3)

Thus, by replacing the expressions of the currents, we have the mathematical model of a photovoltaic cell with one diode which is defined by the equation (4):

$I=I_{p h}-I_{s a t}\left[e^{q\left(\frac{V+I^{*} R_{S}}{V_{t}}\right)}-1\right]-\frac{V+I * R_{S}}{R_{p}}$
Where $V_{t}=\frac{n K T}{q}$ and $I_{R p}=\frac{V+I * R_{S}}{R_{p}}$

With, $\mathrm{n}$ the PN junction ideality coefficient; $\mathrm{K}$ is the Boltzmann constant; $\mathrm{T}$, temperature in Kelvin; $\mathrm{q}$, the electron charge. At a given temperature and irradiation, the expressions of the current saturation $\mathrm{I}_{\mathrm{sat}}$ and the photo-current $\mathrm{I}_{\mathrm{PH}}$ are defined by the equations (5) and (6):

$$
\begin{gathered}
I_{\text {sat }}=I_{\text {sat-ref }}\left(\frac{T}{T_{r e f}}\right)^{3} \exp \left[\frac{-q E_{g}}{n K}\left(\frac{1}{T}-\frac{1}{T_{\text {ref }}}\right)\right] \\
I_{p h}(G, T)=\left(I_{p h-r e f}+\beta \Delta T\right) \times\left(\frac{G}{G_{r e f}}\right)
\end{gathered}
$$

With: Iph-ref: current at the reference temperature Tref;

$\beta$ : temperature coefficient given in the technical sheet;

Eg: width of the forbidden band;

Isat-ref: saturation current at Tref

Applying Newton Raphson's method gives us the I-V and P-V characteristics of the used cell. The characteristics obtained under the influence of the variation of temperature (for a given $\mathrm{G}$ ) as well as the sunshine (for constant $\mathrm{T}$ ) are shown in figures 3 and 4 .
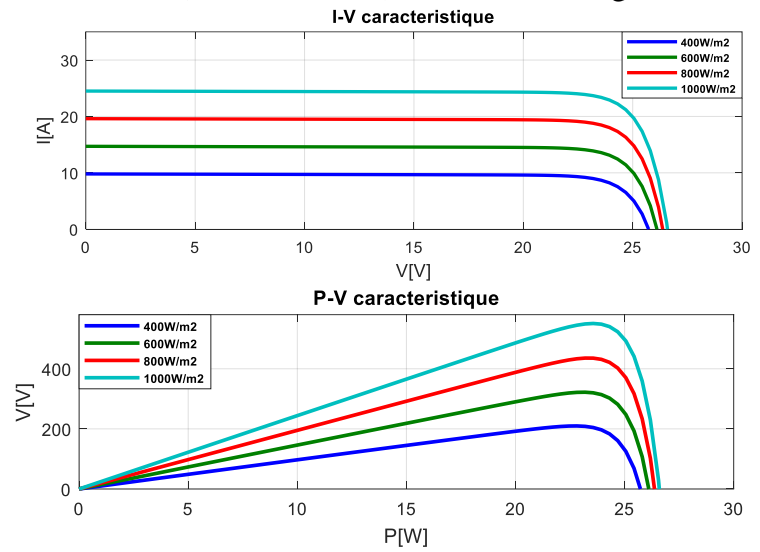

Figure 3. Characteristic PV and IV under the influence of the variation of the sunshine at $T=25^{\circ} \mathrm{C}$
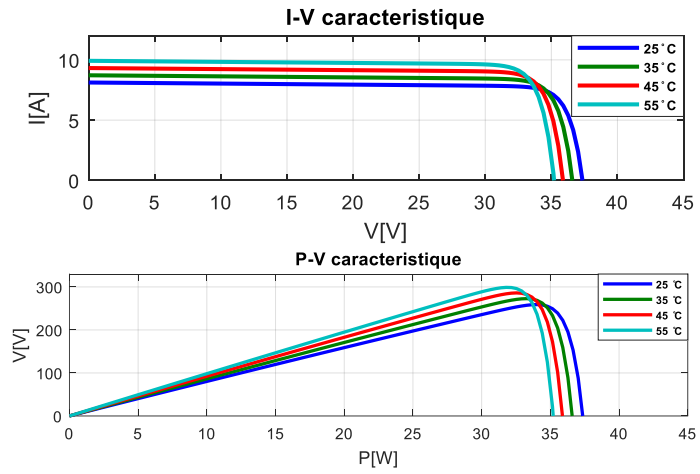

Figure 4. PV and IV characteristic under the influence of the temperature variation for $G=1000 \mathrm{~W} / \mathrm{m} 2$

\section{MODELING OF THE SEPIC CONVERTER}

SEPICs are part of synchronous converters which actually become more advantageous than other kind of converters due to reduced current ripple and better efficiency. However, this converter is not 
yet fully exploited due to the difficulties of output voltage regulation [9]. It is used as interface for the output of the PV generator to the load and to track the maximum power point.

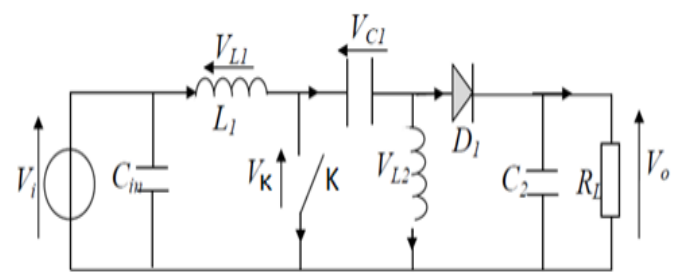

Figure 5. SEPIC converter

The mathematical model of the converter [12] during a switching period $\mathrm{T}$ is given by the equation (9):

$$
\left\{\begin{array}{c}
\frac{d i_{L 1}}{d t}=\frac{1}{L_{1}}\left[(d-1)\left(V_{C_{1}}+V_{C_{2}}\right)+V_{e}\right] \\
\frac{d i_{L 2}}{d t}=\frac{1}{L_{2}}\left[(d-1) V_{C_{2}}-d V_{C_{1}}\right] \\
\frac{d i_{C 1}}{d t}=\frac{1}{C_{1}}\left[(d-1) i_{L_{1}}-d i_{L_{2}}\right] \\
\frac{d i_{C 2}}{d t}=\frac{1}{C_{2}}\left[(d-1)\left(i_{L_{1}}+{\frac{i}{L_{2}}}_{2}\right)-\frac{V_{C_{2}}}{R C_{2}}\right]
\end{array}\right.
$$

And the according Simulink simulation model [12] is shown in figure 6:

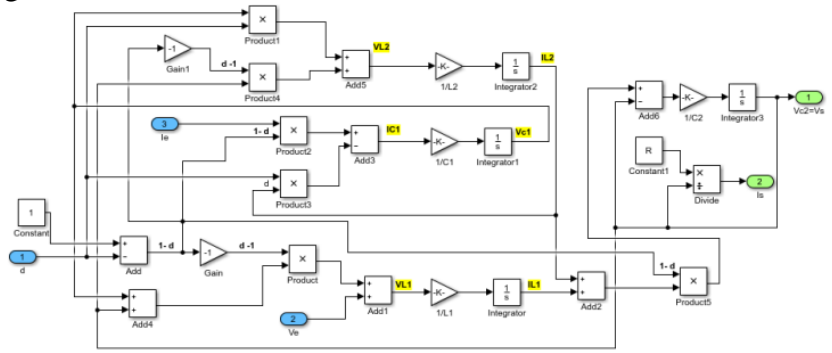

Figure 6. SEPIC simulation model

\section{NEURAL CONTROL}

An artificial neural network can be defined as a set of small computational units linked together by communication links. Each unit, which may locally have a low capacity memory, performs a calculation from data from its connections and from local data [8] [11].

The structure of the neural network is specified to find the appropriate solution for nonlinear and complex systems. Figure 7 shows the architecture of an ANN containing several layers. The input layer receives the external data, the second layer (hidden layer) contains some hidden neurons which receive data from the input layer then send them to the third layer and so on until the last (output layer) [10].

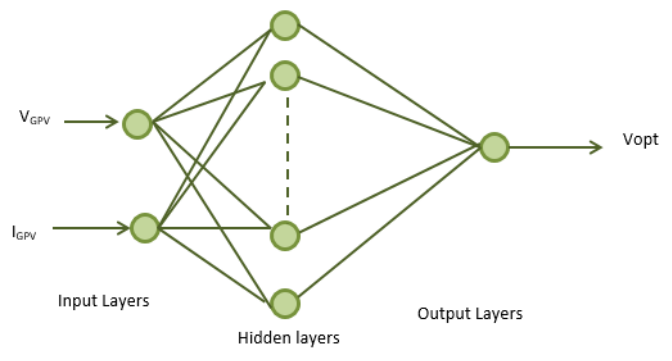

Figure 7. Neural control architecture

The relationship between the outputs of layer $\mathrm{c}$ and the input of neuron $\mathrm{i}$ of layer $(c+1)$ is a linear relationship, in equation (10):

$$
X_{i}^{c+1}(w)=\sum_{j=1}^{n_{c}} w_{i j}^{(c)} \star S_{j}^{(c)}(w)
$$

And the output of a neuron $\mathrm{i}$ of layer $\mathrm{c}+1$, is defined in equation (11):

$$
Y_{i}^{C+1}=f\left(X_{i}^{C+1}(W)\right)
$$

With, $X_{i}^{C+1}$ : the input of neuron $\mathrm{i}$ of layer $\mathrm{c}$ for the element $\mathrm{w}$. $W_{i j}^{(c)}$ : the weight of the connection between cell i of layer $(c+1)$ and cell $\mathrm{j}$ of layer $\mathrm{c}$.

$S_{j}^{(c)}(W)$ : output of neuron i from layer c

$Y_{i}^{C+1}$ : output of neuron $i$ from layer $(c+1)$

The proposed neural MPPT has two inputs such as the voltage as well as the current of the GPV, and a desired output which is the optimal voltage according to the maximum power. That formulation is presented in equation (12):

$$
X=\left[\begin{array}{ll}
V_{G P V} & I_{G P V}
\end{array}\right] \text { and } T=V_{\text {opt }}
$$

\section{System learning}

For the training, we have employed the back propagation technique which is a technique based on the gradient descent algorithm (BP) and uses the derivation rules of the derivable functions [8] [9].

Its objective is to update the weights and biases using the following equations:

$$
\begin{aligned}
& w_{i, j}^{m}(k+1)=w_{i, j}^{m}(k)-\alpha \frac{\partial E}{\partial w_{i, j}^{m}} \\
& b_{i}^{m}(k+1)=b_{i}^{m}(k)-\alpha \frac{\partial E}{\partial b_{i}^{m}}
\end{aligned}
$$

Where, $\alpha$ is the learning step

$\mathrm{E}$ : the cost function which is the quadratic error which minimize the sum of the squares of the errors between the desired output $\mathrm{T}$ and the real value $\mathrm{Y}$ of the network output. It is defined in equation (15): 


$$
E(w)=\frac{1}{2} \sum_{i=1}^{n}\left(y_{i}(w)-T_{i}\right)^{2}
$$

With this algorithm the improvement of the results depends on the value of the quadratic error and the chosen learning step. The smaller the pitch and the cost, the more the voltages and currents will improve.

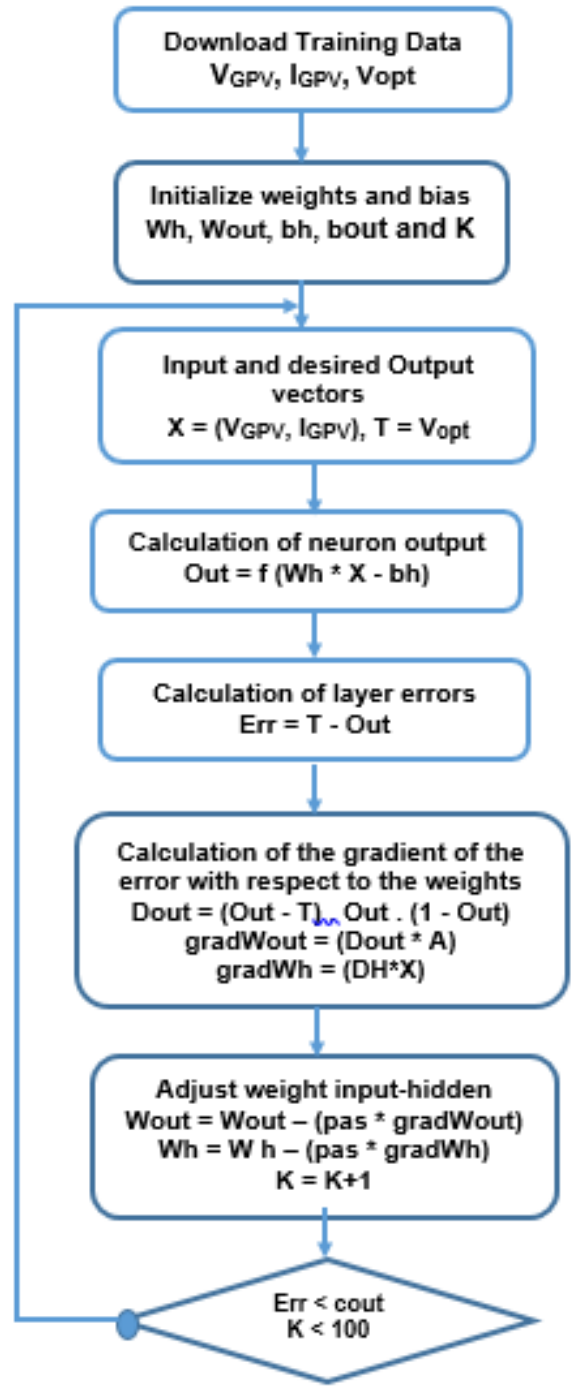

Figure 8. Gradient backpropagation algorithm

\section{MPPT CONTROL AT CONDUCTANCE INCREMENT}

This method is directly addresses power variations as a function of voltage. The conductance is the intensity divided by the voltage, $G=\frac{I_{L G P V}}{V_{G P V}}$, while the incremental conductance is the quotient of the variation, in a time interval, of the intensity with that of the voltage $\Delta G=\frac{\Delta I_{L G P V}}{\Delta V_{G P V}}$. Comparing the conductance $G$ with the incremental conductance $\Delta \mathrm{G}$, allows us to identify the maximum characteristic of the curve PV, by seeking for the cancellation point of the derivative power.

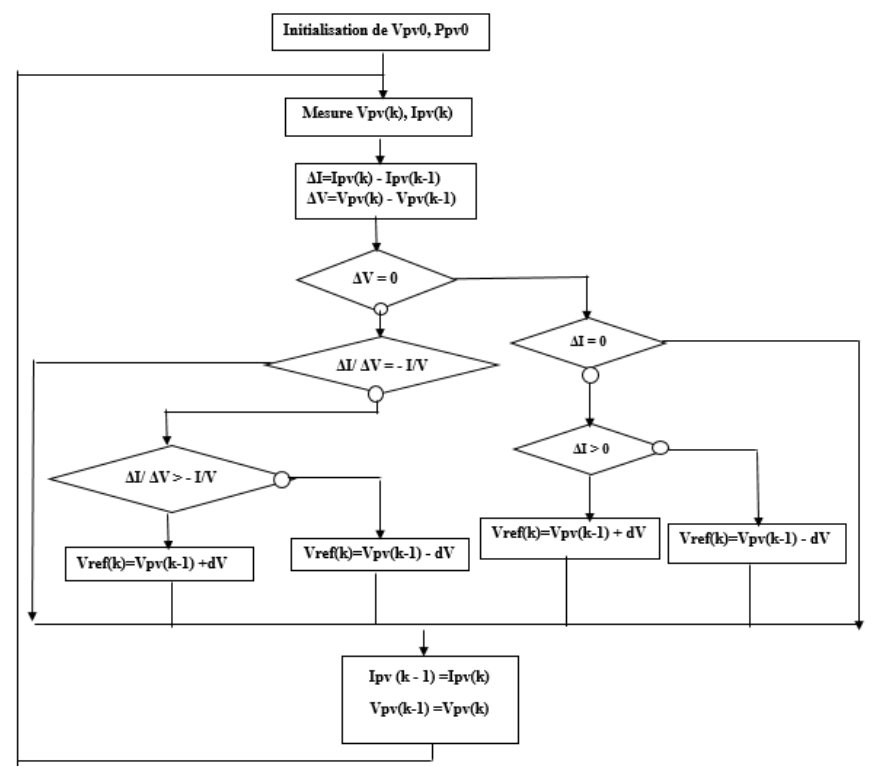

Figure 9. Conductance increment

\section{PI REGULATORS}

Two PI correctors, such as the PI voltage regulator and the PI current regulator, were used in the proposed command:

\section{PI voltage regulator}

This regulation aims to regulate the PV generator voltage around the reference value delivered to the output of the neuron network block. The transfer function of the PI-Voltage regulator is shown in equation (16):

$$
C(s)=k_{p T}+\frac{k_{\text {iT }}}{s}
$$

Where $k_{p T}, k_{\text {iT }}:$ corrector gains

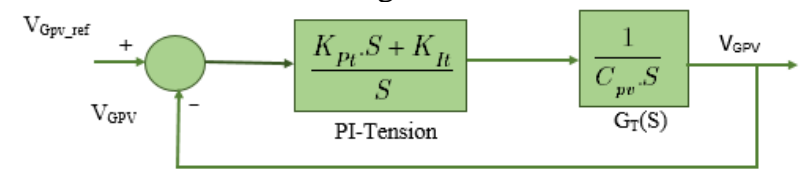

Figure 10. PI regulator

The values of the regulator parameters are obtained by the equations (17):

$$
\left\{\begin{array}{l}
k_{p T}=2 C_{P V} \xi_{W_{n}} \\
k_{i T}=C_{P V} W_{n}^{2}
\end{array}\right.
$$

Where $\xi$ the own pulsation and $W_{n}$ the damping factor.

\section{PI current Regulation}

It regulates the current of coil $\mathrm{L} 1$, and corrects the error between the measured current flowing through coil $\mathrm{I}_{\mathrm{L} 1}$ and the reference provided by the voltage regulation loop of the PV generator [3]. 


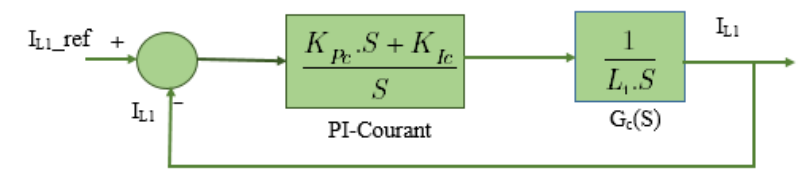

Figure 11. current regulator

With,

$$
\left\{\begin{array}{l}
k_{p C}=2 L_{1} \xi_{W_{n}} W_{n} \\
k_{\text {ic }}=L_{1} W_{n}^{2}
\end{array}\right.
$$

\section{OVERVIEW OF THE SYSTEM}

The whole system is formed by a PV generator composed by twelve panels mounted in series, an MPPT regulator, a threephase inverter with an LC filter and an AC load.

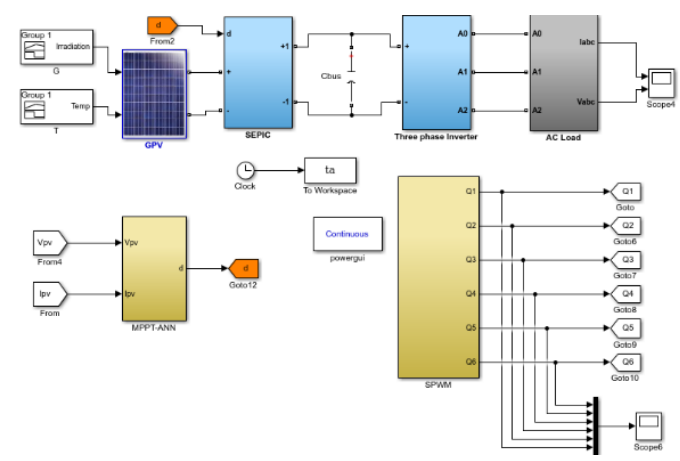

Figure 12. The whole system

The regulation loop contains four Simulink blocks, the ANN block which allows generating the reference voltage of the voltage regulator, then two blocks of PI correctors which control and stabilize the output voltage and current according to their reference. The last block contains the PWM control of the SEPIC converter.

The MPPT-ANN and PI corrector blocks of the control part are shown in the figure 13 and 14 :

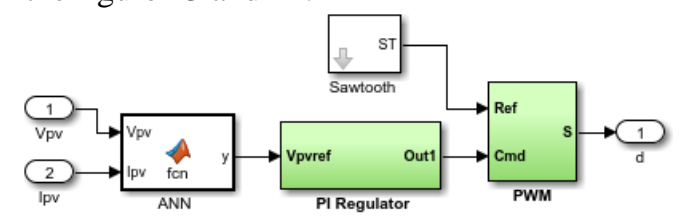

Figure 13. Simulation of the back-propagation algorithm

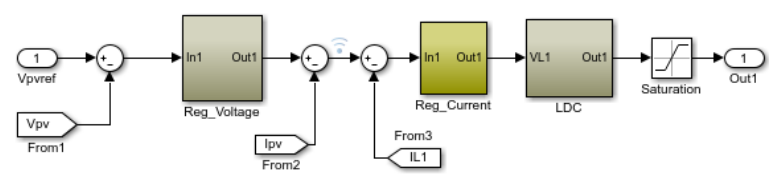

Figure 14. Cascade voltage and current regulator blocks

\section{ANALYZES AND RESULTS INTERPRETATIONS}

The evaluation of the results is done with the observation of the system's behavior according to possible climatic conditions. First, the system is in standard condition (where sunlight $=1000[\mathrm{w} / \mathrm{m} 2]$ and temperature $=25^{\circ} \mathrm{C}$ ). Next, it is exposed to the influence of variations of some external parameters. The figures 15 shows the results obtained under the standard condition. In these figures, we can see that, with the two commands, the system converges rapidly to the optimal values, with a perfect response time (less than $0.05[\mathrm{~s}])$. On the other hand, figures 15-16 show the improvement in system efficiency with the neural regulator compared to INC.
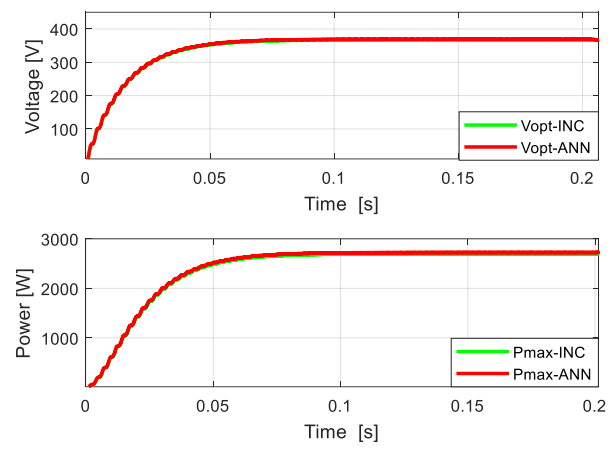

Figure 15. SEPIC output voltage and power
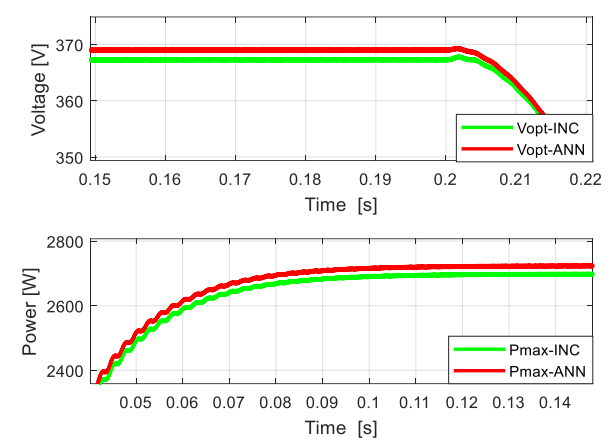

Figure 16. Zooms of the voltage and power

The results in figure 18, shows the behavior of the system under the influence of the simultaneous variation of the two parameters. These results confirm that the controllers work correctly. Indeed, the latter have proven that they have a fast time response and are robust for some variations in atmospheric conditions. However, the zooms of figure 19 confirm that the supplied power by the ANN controller is more satisfactory than that with the INC. The figure 20 presents the voltage and current at the output of the inverter. Note that it is also very sensitive to variations of sunshine and temperature, but, always ensures the load demand.

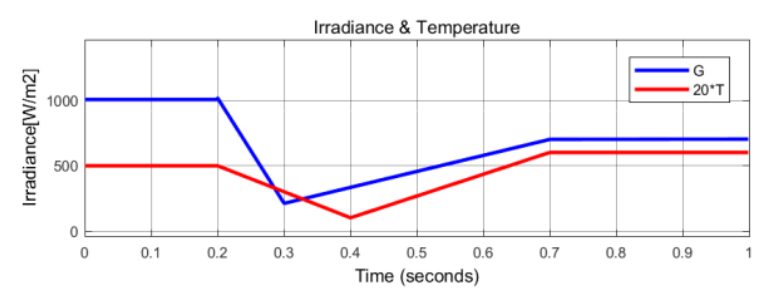

Figure 17. Irradiance and Temperature 

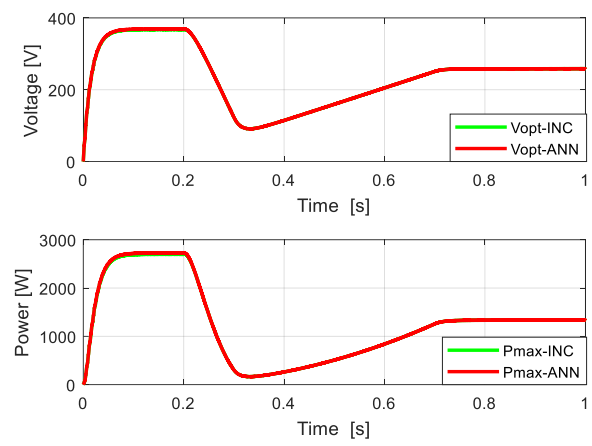

Figure 18. Output voltage and power under the influence of atmospheric parameters
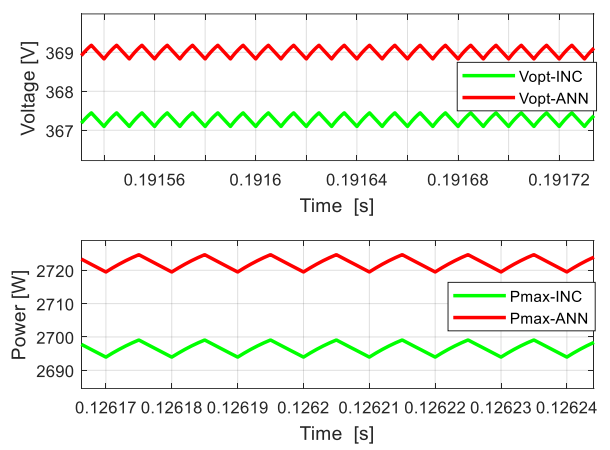

Figure 19. Zooms of the paces of figure 18

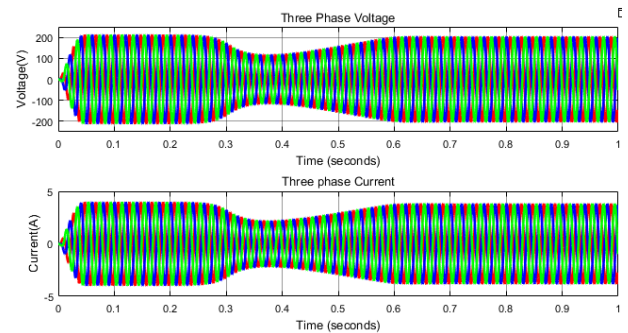

(a)

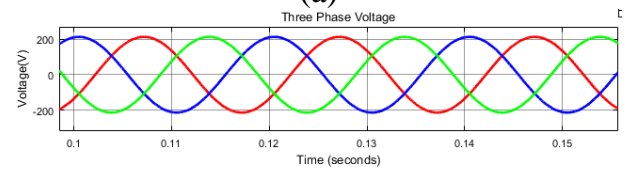

Thee

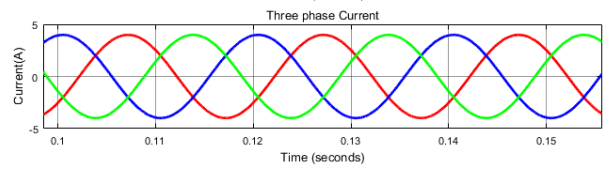

(b)

Figure 20.(a) Three-phase voltage and current at the output of the inverter, (b) zooms of the sub-figure (a)

TABLE I. Parameters of the SEPIC converter

\begin{tabular}{|c|c|c|}
\hline Description & Symbols & Values \\
\hline Resistance & $\mathrm{R}$ & $50[\Omega]$ \\
\hline Inductors & $\mathrm{L} 1, \mathrm{~L} 2$ & $10.39[\mu \mathrm{H}]$ \\
\hline & $\mathrm{Ce}$ & $4.7[\mu \mathrm{F}]$ \\
Capacity & $\mathrm{C} 1$ & $5[\mu \mathrm{F}]$ \\
& $\mathrm{Cbus}$ & $1.156[\mu \mathrm{F}]$ \\
\hline
\end{tabular}

This publication is licensed under Creative Commons Attribution CC BY. http://dx.doi.org/10.29322/IJSRP.11.12.2021.p12024
TABLE II. GPV settings

\begin{tabular}{|l|c|c|}
\hline \multicolumn{1}{|c|}{ Description } & Symbols & Values \\
\hline Maximum Power & Pmax & $246[\mathrm{~W}]$ \\
\hline Voltage at Pmax & Vmp & $32.2[\mathrm{~V}]$ \\
\hline Current at Pmax & $\mathrm{Imp}$ & $7.62[\mathrm{~A}]$ \\
\hline Open-circuit voltage & Vco & $37.40[\mathrm{~V}]$ \\
\hline Short-circuit current & Isc & $8.12[\mathrm{~A}]$ \\
\hline Number of Cells in series & $\mathrm{Ns}$ & 36 \\
\hline Number of modules in series & $\mathrm{Ms}$ & 12 \\
\hline Number of modules in parallel & $\mathrm{Mp}$ & 1 \\
\hline
\end{tabular}

\section{CONCLUSION}

In this article, we have presented the modeling and simulation of an autonomous PV system with a neural MPPT control. This command is used to control the duty cycle of a SEPIC converter. The performance and efficiency of this neural MPPT algorithm has been clearly proven compared with other command.

The obtained results from the simulation show that the controller allows the system to react well to restore, almost totally the PPM, where the transmitted power to the load is the maximum. The servo-control has a good performance in term of precision, speed and stability. It has also a good ability to follow.

\section{REFERENCE}

[1] Ch. Kiran Kumar, T. Dinesh, Ganesh Babu "Design and Modeling of PV system and Different MPPT algorithms" International Journal of Engineering Trends and Technology (IJETT) - Volume 4 Issue 9- Sep 2013

[2] Liu, B; Duan, S; Liu, F. and Xu, P. "Analysis and Improvement of a Maximum Power Point Tracking Algorithm Base on Incremental Conductance Method for Photovoltaic Array." IEEE International Conference on, 2007, pp. 637-641.

[3] P. Sanjeevikumar, G. Grandi, PW Wheeler, F. Blaabjerg, J. Loncarski, "A Simple MPPT Algorithm for Novel PV Power Generation System by High Output Voltage DC-DC Boost Converter", IEEE Trans. Power Electron, pp. 234-240, 2015.

[4] S. Gueye, I. Gueye, L. Thiaw, G. Sow, A. Ndiaye, M. Thiam, "Design of a solar regulator with MPPT control”, CAMES Vol. 1 (2), pp. 104-108, January 2015,

[5] Divyansh Mathur," Maximum Power Point Tracking with Artificial Neural Network". International Journal of Emerging Science and Engineering, ISSN: 2319-6378, Volume-2, January 2014

[6] Mahmoud A. Younis, Tamer Khatib, M.Najeeb, A Mohd. Ariffin “An Improved Maximum Power Point Tracking Controller for PV Systems Using Artificial Neural Network”, ISSN 0033-2097, R. 88 NR 3b / 2012, Pg. 116-121.

[7] TM Vishnu Kumar, G. Uma, "Intelligent Controller for Maximum Power Point Tracking Control of Solar Power Generation System”, International Journal of Engineering Research and Applications, Vol. 3, Issue 1, January February 2013, pp. 1965-1969

[8] AM Zaki, SI Amer, M. Mostafa, "Maximum Power Point Tracking for PV System Using Advanced Neural Networks Technique", International Journal of Emerging Technology and Advanced Engineering, ISSN: 2250-2459, Volume 2, Issue 12, December 2012

[9] M. Kaouane, A.Boukhelifa and A.Cheriti, "Design of a synchronous SEPIC converter for a standalone photovoltaic system", IEEE 28th Canadian conference on electrical and computer engineering, Vol.2. May, 2015.

[10] T. Shanthi, SUPrabha," Neural Network Based MPPT Controller for Solar PV System" International Journal of Innovative Technology and Exploring Engineering (IJITEE) ISSN: 2278-3075, Volume-8 Issue-2S2 December, 2018

[11] R.Ramaprabha, Member, IEEE, BLMathur and M.Sharanya, "Solar Array Modeling and Simulation of MPPT using Neural Network" Proceedings of 
International Conference on Control, Automation, Communication and Energy Conservation (INCACEC'09) JULY 2009

[12] R.Solofanja Jeannie, R Jean Marie, A. Yvon, "Comparative Study of SEPIC Converter Commands Fitted with Classic MPPT Algorithms Combined with Two Cascaded PI Correctors" International Journal of Engineering Research \& Technology, ISSN: 2278-0181, Vol . 9, Issue 06, June-2020

\section{AUTHORS}

First Author - RAJONIRINA Solofanja Jeannie $\mathrm{PhD}$ student, Thematic doctoral school of the environment and renewable energy, University of Antsiranana,

Madagascar,

Email:rajonirinas@gmail.com

Second Author - RAZAFIMAHENINA Jean Marie
Professor, Information and Communications Sciences and Technology Department, Polytechnic School, University of Antsiranana, Madagascar

Email: razafimaheninajeanmarie@yahoo.fr

Third Author - RAOELIVOLOLONA Rakotobe Tefy $\mathrm{PhD}$, Information and Communications Sciences and Technology Department, Polytechnic School, University of Antsiranana, Madagascar

Email:vololonatefy@gmail.com

Fourth Author - ANDRIANANTENAINA Chrysostome $\mathrm{PhD}$ student at the Thematic doctoral school of the environment and renewable energy, University of Antsiranana, Madagascar Email:chrysmamitiana@gmail.com 